\title{
EL CONTINUO DAR EN OTRA COSA DE EDUARDO MILÁN: SÍMBOLO, ALEGORÍA Y FRAGMENTO
}

\author{
Pablo López Carballo \\ Duke University in Madrid, Madrid, España \\ p194@duke.edu
}

\section{RESUMEN / ABSTRACT}

En la obra de Eduardo Milán encontramos un constante empleo de estrategias simbólicas y alegóricas -recursos con un carácter marcadamente metonímico-, en detrimento de otros recursos más habituales en el uso, como los recursos metafóricos. Estos procedimientos, que el autor considera de especial relevancia por su alcance y posibilidades, ponen de manifiesto sus ideas en torno al lenguaje. Así, la inestabilidad del material lingüístico, donde no es posible delimitar unívocamente sentidos o referencialidades, se resuelve elemento indispensable a la hora de analizar su obra poética. Nos centraremos en una fase temprana de su poesía, concretamente en las publicaciones que comprenden el periodo 1990-1994, por resultar especialmente significativa de acuerdo al propósito inicial y por adoptar en estos años el fragmento como unidad básica en su creación.

PALABRAS ClaVE: Eduardo Milán, poesía hispanoamericana, alegoría, símbolo, fragmento.

\section{EDUARDO MILAN'S CONSTANTLY REACHING SOMETHING ELSE: SYMBOL, ALLEGORY AND FRAGMENT}

Eduardo Milán's oeuvre is characterized by constant recourse to symbolic and allegorical strategies - as charged with a specifically metonymical function-to the detriment of other traditional rhetorical devices, such as those related to metaphor. These strategies, which the author considers as especially relevant for their scope and creative possibilities, clearly show his authorial stance towards language. Therefore, it is the instability of language, which does not allow the univocal determination of meanings and referents, which can be devised as a crucial aspect in the analysis of Milán's poetry. Consequently, this paper focuses on an early stage of his poetry (1990-1994), in which the author uses the fragment as the basic unit for his creative processes.

KEYWORDS: Eduardo Milán, Latin American poetry, Allegory, Symbol, Fragment. 


\section{INTRODUCCIÓN}

La poesía de Eduardo Milán (Rivera-Uruguay, 1952) muestra una clara tendencia hacia la tensión entre el texto y lo real, con una insistente inclinación al cambio, como bien ponen de manifiesto los diferentes acercamientos a su obra (Casado; Méndez Rubio; Mendiola; Ochoa). Ante esta situación, se resuelve necesario encontrar herramientas de análisis que nos permitan una mayor sistematización y ayuden a la comprensión. Por eso, consideramos que las nociones de símbolo, alegoría y fragmento responden a las exigencias planteadas. Esta elección se apoya en la hipótesis de que representan tres de las estrategias más importantes de su trabajo lingüístico, dada la presencia constante que mantienen a lo largo de toda su trayectoria artística. En definitiva, estos mecanismos representan la óptica idónea desde la que aproximarse y comprender la poesía de Milán, debido a su capacidad para aglutinar gran parte de los propósitos en los que se basa su concepción estética.

En este sentido, tanto el símbolo como la alegoría se entienden aquí como recursos expresivos desde los que, por un lado, articular la compleja relación entre escritura poética y realidad y, por otro, cifrar el alcance semántico de la representación estética en esta obra. No en vano, ya a principios del siglo pasado, Walter Benjamin se preguntaba: “¿cómo es posible que un procedimiento tan "intempestivo" en apariencia como lo es el del alegorista tenga un lugar tan prominente en la obra poética del siglo?" (Charles Baudelaire 285). Sin embargo, no estará entre nuestros propósitos ofrecer una respuesta a la cuestión planteada por el filósofo alemán, aunque esta sí que resultará pertinente a la hora de destacar la conveniencia e importancia de un procedimiento, como también lo es el simbólico, ampliamente utilizado, de diversas formas y en diferentes épocas y contextos, por la poesía contemporánea. En este aspecto, la obra de Eduardo Milán mantiene una vinculación más estrecha con estos mecanismos, antes que con otras figuras de la variada gama que puede asumir la escritura literaria. Así, en una entrevista realizada por Miguel Ángel Zapata, el poeta señala una serie de apreciaciones en torno a varios tipos de recursos que sin duda apoyan la selección metodológica que planteamos:

trato de no caer en la metáfora. Si hablamos de figuras, te diré que me siento más cerca de la metonimia, que es el arte de la prolongación, del devenir, del continuo dar en otra cosa. En otras palabras: prefiero tocar y seguir que petrificar un espacio. Y la metáfora, creo, funda, es decir, construye futuras ruinas, petrifica (248). 
Partiendo de este planteamiento, esta petrificación de la que habla el poeta es, precisamente, una de las cuestiones a tener a cuenta en este trabajo, debido al carácter variable que atraviesa su obra. En esta misma dirección, el análisis deberá mantener la ya apuntada consonancia con nuestro objeto de estudio, para no condicionar o anular la inclinación al cambio, el "devenir" que mencionaba el autor. Por eso, las nociones de símbolo y alegoría-figuras metonímicas- nos ayudarán en la tarea de dar cuenta de la tensión que se produce entre el lenguaje y el mundo en la poesía de Eduardo Milán. Así, después de revisar las acepciones que caracterizan a las dos figuras, y pese a su compleja delimitación formal, trabajaremos en las que más se aproximen a ese "continuo dar en otra cosa" referido por el poeta uruguayo. Es decir, nos serviremos de las aportaciones ofrecidas por aquellas vías de análisis que entienden el símbolo como la manifestación ambigua de la idea y la alegoría como elemento que trata, mediante lo que está, de lo que no está presente. En ocasiones de manera complementaria y en otras como resultado de estos procesos, el fragmento se resuelve como una unidad mínima desde la que parte la creación. Desaparece así la totalidad a la que hacer referencia, o la intención de ofrecer al lector un poema que muestre una clara delimitación de algo completo.

\section{PERIODIZACIÓN}

En el periodo inmediatamente anterior a los primeros años de la década de los noventa, el que comprendería las publicaciones Estación, Estaciones (1975), Esto es (1978) y Nervadura (1985), se afianza una visión en torno al hecho poético basada en la creación de un tejido lingüístico capaz de vincular poesía y mundo -o dicho de otro modo: establecer conexiones con el afuera del texto- de manera que no se especule con la complejidad de ninguno de los polos. Si bien en las siguientes publicaciones de las que hablaremos, Cuatro poemas (1990), Errar (1991), La vida Mantis (1993) y Nivel medio verdadero de las aguas que se besan (1994), seguimos encontrando esta misma idea general sobre la escritura, sí podemos advertir algunas diferencias que determinarán otros planteamientos. Así, en Cuatro poemas, un libro que podríamos considerar de transición entre Nervadura y Errar, ya visualmente se observa un cambio con respecto a sus anteriores publicaciones: los poemas han dejado de estar atravesados por silencios espaciales, tornándose así textos más compactos, donde el poeta, a pesar de seguir manteniendo una fuerte 
conciencia de su aspecto - de la disposición de la escritura en la página en blanco-, busca construir la forma o estructura de la composición desde una perspectiva diferente. Así lo ha entendido Nicanor Vélez, quien refiriéndose a este cambio subraya que: "Desde el punto de vista formal [...] en la mayoría de sus poemas el concepto de estrofa desaparece, es decir, el poema visto como fachada es un "bloque sin forma" (22). En este sentido, Cuatro poemas ejemplifica el proceso de cambio, siendo un término medio entre los dos paradigmas, aunque ya decantado hacia un nuevo posicionamiento poético. Como ejemplo, en el siguiente texto podemos ver cómo funciona este tipo de construcción poemática:

El pájaro no tiene vacío

el cielo nace de su carencia su vuelo es la ocupación del cielo

el cielo trabaja

pero el pájaro no tiene

cultivar tu vacío

como una estatua cultiva

su interior jardín

vacío de voces y de pájaros

no es posible llenarlo de follaje

espeso

no es posible llenarlo de palabras

ni de livianos labios

son plumas

esto no es decir

esto es estar

esto es estrella (59-60).

Además del aspecto visual del texto, encontramos ciertos rasgos que conviene precisar. Continuando con la comparación con el periodo precedente, en ambos encontramos una defensa de la ambigüedad contenida en símbolos clave en su escritura como "pájaro" o "estrella", mostrando con ello las limitaciones del lenguaje e intentando tender puentes, en este caso concreto mediante la contraposición de la idea de "estar" frente a la de "decir". Se produce, de este modo, un cambio de ubicación del sujeto poético que si en una primera etapa se situaba en un espacio desde el que aprende el exterior en el interior del poema, muda su escenario por el que más inmediatamente le rodea. Es entre estos dos polos donde oscila la obra del periodo, sin que en ningún momento 
haya una renuncia total hacia alguno de ellos. Si bien se podrían rastrear en publicaciones posteriores tanto los mismos usos como las remisiones e intertextualidades, hemos preferido centrarnos en el periodo destacado por ser donde tienen una predominancia clave y más constructiva. Posteriormente, estas estrategias se vuelven subsidiarias de otras y no funcionan del mismo modo. Los vínculos que se podrían establecer son de diferente naturaleza y no siempre responden a las mismas motivaciones, llegando incluso a ser contradictorios entre sí. Aquí no podremos detenernos en ello porque tal tarea requeriría un estudio exhaustivo y detenido, con unos planteamientos específicos, diferentes a los empleados para este análisis, que aborden la complejidad de dicha propuesta en toda su dimensión.

\section{AMBIGÜEDAD SIMBÓLICO-ALEGÓRICA}

La mirada del poeta se desplaza hacia un espacio intersticial, donde el lenguaje y el afuera del texto mantienen fricciones. En esta zona de contacto es donde cobran especial relevancia los recursos alegóricos y simbólicos. En nuestra historia reciente han aparecido como pares conceptuales de difícil desvinculación. Con ello, se ha propiciado un tipo de acercamiento a ambos recursos que tendía a la definición en conjunto, es decir, que para definir a uno fuese ineludible la recurrencia al otro, llegando incluso a negar la validez de la forma en contraste frente a la supremacía de la que se pretendiera analizar. Bien sea para validar la noción de símbolo o, como señala Todorov, para "oponerse a todo cuanto no sea ellos mismos" (Teorías del símbolo 280), ambos conceptos se han visto modificados y matizados en la confrontación, que encontrará un segundo punto álgido después del Romanticismo alemán, y su lado opuesto, con Walter Benjamin.

Es a partir de los planteamientos de Hegel, Goethe y Schelling cuando de forma más evidente resulta posible establecer la confrontación entre ambos procedimientos. Así, si bien estas posturas tienen en común una idea de aquellos que hace inevitable su oposición, cada una de ellas mantiene una posición diversa en cuanto a los términos interpretados. Así lo hace notar Peter Szondi en relación tanto con el concepto de símbolo, como con el de alegoría:

Aunque las concepciones de Goethe, Schelling y Hegel están muy relacionadas con respecto al símbolo y la alegoría, la terminología hegeliana se diferencia mucho de la de Schelling y la de Goethe. 
La completa interpretación mutua de finito e infinito, la unidad, por tanto, de significante y significado, es símbolo en Schelling y Goethe. Hegel, por el contrario, denomina símbolo a lo que en Schelling y Goethe se llama alegoría en tanto opuesto de dicha unificación total: la separación de significante y significado (132).

Con ello se explica que a pesar de coincidir en la capitalidad de tales nociones, sus propuestas hermenéuticas puedan llegar a ser contrapuestas o, incluso, excluyentes, según lo apuntado anteriormente. También se pone de manifiesto el hecho de que para algunos románticos, como Schlegel, la indeterminación del símbolo y la alegoría sea algo plenamente positivo y, para otros, como los mencionados más arriba, algo reprobable.

Ahora bien, las posibilidades abiertas por este tipo de concepciones implican que la gestión de sus significados realizada desde la actualidad pueda servirse de todas ellas, elaborando nuevos caminos y estaciones de actuación. Y con ello se explica una postura como la de Eduardo Milán, quien opta por la ambigüedad de ambos -recursos especialmente en cuanto al símbolo- resaltando en su poesía la inexistencia de una relación unívoca y directa entre palabra y objeto. Tal propuesta, rastreable en publicaciones recientes como Habla (2005), Acción que un momento creí gracia (2005)', Obvio al desnudo (2009), Disenso (2010) o Donde no hay (2012), aparece en la obra de este poeta tanto desde el punto de vista formal como temático, haciendo de su escritura un constante pulso crítico en torno a la producción literaria de realidad mediante los procedimientos simbólico y alegórico. Es este tipo de ruptura la que permite al poeta mantener un terreno de creación, un espacio abierto, como "herida", diría el mismo autor, para la escritura poética, "la apariencia impide la llegada de las palabras. ¿Rechaza el mundo? No, rechaza una forma del mundo donde las palabras en apariencia están encarnadas secularmente" (Nivel medio verdadero 16). De este modo, se aúnan los procedimientos simbólico y alegórico, dejando apartadas las premisas que establecen una vinculación directa y delimitable entre figura y

\footnotetext{
Como ejemplo, en este libro encontramos una revisión de modos poéticos, acontecimientos históricos y personales, que trata de obtener nuevas perspectivas y posibilidades en torno a ellos. En este sentido, tendríamos los versos como "en el tiempo en que leía por epifanía / - epifanía es una palabra posterior" (24) o "mención de una flor que en un instante creía bella / mientras permaneció la imagen" (23), variante de procedimientos empleados en "Noche textual".
} 
realidad. De ahí que podamos encontrar versos que se muestran reveladores al respecto, destacando en este periodo los que involucran símbolos como el pájaro: "El mirlo tiene del mar / la mirada sobre ambos" (Cuatro poemas 60). De igual modo, en libros posteriores como Ostras de coraje (2003) podemos observar estas mismas dinámicas. En este mismo sentido, Antonio Ochoa señala que "la imagen del pájaro como la palabra que puede atravesar el espacio entre el poeta y la realidad" (236) es fundamental para comprender el posicionamiento estético de Milán. Este pájaro, con variadas formas y especies, será un símbolo recurrente en el conjunto del poeta que, a pesar de asumir diversas funciones a lo largo de los diferentes textos en los que aparece, siempre apunta hacia la posibilidad de establecer conexiones entre esferas presumiblemente independientes. Sin embargo, el hecho de que pueda considerarse como una constante de su escritura, no deriva en la conclusión de que estas conexiones tiendan a establecerse de manera directa, unívoca y clara, sino que, por el contrario, se inclinan más bien por un tipo de manifestación en continuo cambio, oscilante, autorreferencial y/o volátil. El propio autor, en un texto en el que busca dar cuenta de algunas palabras o conceptos presentes de manera constante en su poesía, se manifestaba así sobre el símbolo del pájaro:

A mí también me gustaría que en el pájaro no hubiera ningún misterio. Pero hay. Que en el canto no hubiera ningún misterio. Pero hay. Y ninguno en el vuelo. Pero hay. El misterio consiste en la fragilidad, en la fuerza de la fragilidad. El mundo es muy grande y el pájaro muy pequeño. El lazo que establecen ambos crea un ámbito de hospitalidad recíproca: uno hace de caja de resonancia y el otro de sonido. Y el otro -que viene a ser uno mismo- escucha (Zapata 119).

En este sentido, resulta especialmente relevante que uno de los símbolos con más presencia se presente en perpetua fuga y errancia, dejando en múltiples ocasiones únicamente una huella, el vuelo o la presencia de la ausencia o, en palabras de Víctor Manuel Mendiola: "una poesía de lo que va a suceder o de lo que ya sucedió, y ahora es una estela, o de lo que ha sido largamente preparado con un indemostrable teorema, pero que no ha logrado colmarse ni refrenarse" (12). Se establece, de este modo, un permanente espacio de tránsito, imposible de delimitar cartográficamente, y que precisamente gracias a esa ausencia de límites perfectamente definidos permite la confluencia -o mejor sería hablar de momento de gracia- del lenguaje con el mundo. 
Esta actitud se encuentra claramente expresada en Errar, libro capital, del año 1991, que sin duda instaura todas las bases de esta nueva etapa en la obra de Eduardo Milán. Como se aventuraba previamente, a partir de este volumen comienza a tener una importancia indiscutible el uso del fragmento como unidad mínima gramatical de trabajo en la composición. Tal preponderancia del fragmento hace que el modelo de poema ensayado por el autor con anterioridad, en el que lo visual cobraba un peso indiscutible, se vea desplazado significativamente por una utilización diversa de los ejes sintagmáticos. Así, aunque el texto no pierde su dimensión visual-espacialmaterial, sí adopta una forma diferente, ya no repleta de vacíos o silencios susceptibles de ser interpretados, sino gobernada por una estructura incompleta que establece relaciones incesantes entre sus precarios componentes. En este sentido, ahora el poema mantiene una apariencia más compacta que, a pesar de presentarse de manera menos radical en cuanto a su aspecto exterior se refiere, continúa proponiendo una perspectiva igual de subversiva en relación con el lenguaje poético y sus virtudes y defectos semánticos.

La relación poesía y mundo sigue centrando en Errar las intenciones del poeta, manifestando de manera explícita lo complejo de su vinculación a través de las ideas de falla, abertura, contacto entre esferas, que nos ponen en la línea de procedimientos de construcción de sentido basados en símbolos clave para Milán como el de la herida: "esta herida no se cierra" (23), "el sol abrió la herida" (24) o "Real, la herida" (24). Se observa aquí, en esta elección simbólica, una característica interesante para nuestro trabajo, que consiste en que esta "herida" está en permanente apertura, funcionando, por tanto, como zona intermedia y de conflicto entre el interior y el exterior, el poema y la realidad. Este procedimiento simbólico tendría a su vez un correlato alegórico, desde el que se entiende esta zona como un territorio en el que no funciona la referencia directa, aquella que se limita a señalar lo existente, puesto que, siguiendo lo que Walter Benjamin ejemplificaba con Baudelaire: "la devaluación del mundo de las cosas al interior de la alegoría es superada por la mercancía dentro del mundo de las cosas mismo" (Charles Baudelaire 267). De esta manera, siendo aquí la mercancía el lenguaje cosificado, nos encontraríamos con el hecho de que este devalúa las cosas en el mundo real mucho más de lo que la alegoría devalúa las cosas en la ficción. Es decir, por mucho que la poesía no respete el orden fenomenológico más inmediatamente aprehensible $\mathrm{y}$, en el caso del símbolo y la alegoría, incluso llegue a trastocar el significado habitual de las palabras, esta operación será mucho más honesta y próxima a lo real que cualquier proceso de homogeneización extrema del lenguaje. 
Así, la poesía de Eduardo Milán no se propone como simple mercancía, esto es, un producto que trastoca su valor de uso por el de cambio, que pasa de manos del autor al lector sin llevar a cabo ningún tipo de actuación, sino que aquí el cambio de función lingüística de las estrategias empleadas en el texto hace que su poesía entre en permanente fricción con el mundo. En definitiva, una herida abierta que no puede cerrarse sin que el vínculo que el poeta establece entre su escritura y la realidad corra peligro de desaparecer. Estas zonas intersticiales y de conflicto, de las que Milán hace su lugar de trabajo, pueden apreciarse de forma notoria en el primer poema de Errar:

Ni arco ni flecha: sólo

tensión. Casi se diría Oriente

donde la ciencia del pájaro no

se enciende a mediodía. Ni pájaro ni plumas:

sólo el encendido fuego. Debajo

del pájaro, debajo del tajo del mediodía

esta herida no se cierra por encendida,

por empecinada nada, por el puro eco

de una cara a otra cara. Por carente (23).

El poema propone así quedarse con la "tensión", el "fuego", no con el "arco", las "flechas", el "pájaro" o sus "plumas", ya que como se señala en el último verso, existe una carencia, un vacío objetual que el lenguaje debe salvar, habitando una herida permanentemente abierta. De esta manera, la estrategia alegórica, mediante la cual un referir continuo se torna posible, se convierte en el principal motor del poema, así como en espacio figurativo desde el que lograr actuar en ese punto intermedio en el que se establece el contacto de la poesía con el mundo ${ }^{2}$. Asimismo, la aparente devaluación asociada a la carencia, esconde una idea que Víctor Manuel Mendiola plantea del siguiente modo:

La destrucción o la idea de la destrucción. La emergencia de la poesía de Eduardo Milán muy probablemente resida no sólo en la conciencia aguda de este hecho sino en haber transformado en el espacio de su

2 Esta dialéctica ha sido expresada de modo sustancial por José Luis Brea al definir la alegoría estética como: "pura potencialidad de enunciación de algo otro que concierne al espacio de la representación, experimentación orientada al suspenso -o al menos, a la puesta entre paréntesis- de la literalidad enunciativa" (50). 
trabajo este asunto, en claro contraste con aquel otro discurso que cree que el pensamiento de la poesía puede ser eliminado de golpe sin mayor trámite a favor de una escritura, sin mediaciones, sobre la vida - más ahora que parece afirmarse en todos los ámbitos una solución pragmática no tan diferente a la solución "realista" que también vivía hipnotizada por el sentido común (10).

Así, lo que en Baudelaire se veía en términos de mercantilización, es decir, el vaciamiento de la palabra con fines alegóricos, en Milán supone una huida del recurso fácil, de la literalidad y, por tanto, la configuración de nuevas vías de unión entre realidad y poema. Al mismo tiempo, Mendiola nos pone sobre la línea interpretativa marcada por las propias estructuras planteadas por el poeta, dejando claras las ideas de "que no puede haber presentación sin una representación y de que no es posible escribir sin considerar los procesos de construcción y deconstrucción que han sufrido la escritura, el pensamiento y la realidad" (11). Elementos que, de forma imprescindible, hay que tener en cuenta a la hora de acercarse a la obra de Eduardo Milán. Es de esta manera como el título del libro cobra un nuevo sentido gracias al final del primer poema, "por carente", aludiendo en este caso a un vacío en la posibilidad de acertar de lleno en algo ${ }^{3}$, de dar en el blanco, de dejar las cosas claras y con un sentido accesible y petrificado. La imposibilidad, en definitiva, de proceder de manera directa como si de un proceso de écfrasis se tratase en el que las dos partes que conforman la composición estuvieran perfectamente definidas y delimitadas. Sin embargo, todo esto no quiere decir que se esté llegando a un punto de agotamiento, de imposibilidad de decir, sino que precisamente, a través de la alegoría, se haría posible crear sentidos. Ahora bien, para ello es necesario que el poeta se coloque en un lugar muy particular, por formularlo así, en el medio de dos hemisferios muy diferentes que tiene que "traducir", para hacer que se entiendan, entenderlos y transmitirlos en la representación. En este sentido encontramos en siguiente poema:

Cuando ya no hay nada qué

decir, decirlo. Dar

3 No en balde, una de las dos citas iniciales de La vida mantis es el siguiente texto de Lezama Lima: "El desacierto en poesía puede contribuir a la integración del sentido de poesía. Sin embargo, el acierto es mucho más peligroso, está siempre atraído por la suma de los aciertos homogéneos" (Chacón 293). Se trata de una anotación de un diario fechada el día 25 de octubre del año 1939. 
una carencia, un hueco en la conversación, un vacío de verdad: la flor, no la idea, es la diosa de ahí (43).

De esta manera se accede a un territorio de incertidumbre en el que siempre se está en suspenso pero que a su vez es el que da la oportunidad de que surja el "qué / decir". Esta idea se ve apoyada por unos cortes versales, que más que como encabalgamiento retóricos, podrían ser entendidos en tanto que acantilados, bien sea visuales, bien rítmicos. La intención, por tanto, del poeta no sería, o no solo, que el lector experimente el encabalgamiento en la lectura del final de verso, sino más bien generar una incerteza e incertidumbre, un significado otro, que den cuenta de la tarea en la que se circunscribe el poeta. Así, la máxima de la alegoría como "ambigüedad al nivel del enunciado que tiene dos interpretaciones coherentes" (Todorov, Literatura y significación 225) encuentra en Milán su presencia gracias a la potencialidad de la imaginación y, en muchos casos, mediante un complejo uso de símbolos recurrentes como el pájaro -la alondra u otras especies-, pero también a través de la configuración de un escenario sobre el que ir colocando palabras (27).

Una tarea que, en virtud de la ambigüedad reclamada desde el uso de símbolos inestables y de un concepto de realidad dinámico, no basará su quehacer en constructos homogéneos, completos y paradigmáticos. Más bien, como señala Jean Franco refiriéndose a la literatura latinoamericana de después de la Segunda Guerra Mundial y hasta bien entrados los años ochenta, el poeta entenderá que: "la comunidad, la identidad y la subjetividad han tenido que ser repensadas o recreadas a partir de fragmentos o ruinas" (246). Y es que son precisamente estos fragmentos o ruinas unos de los componentes más importantes en la escritura de Milán, ya que, tal y como se verá a continuación, representan el material de trabajo idóneo para un tipo de textos con marcado interés plurisignificativo.

\section{EL FRAGMENTO Y LA PRÁCTICA ALEGÓRICA}

Así como hasta el momento se han ido resaltando las nuevas aportaciones o cambios de perspectiva sobre la escritura que Eduardo Milán desarrollaba a lo largo sus primeras publicaciones, en lo concerniente a la noción de fragmento resulta posible afirmar que representa una práctica constante en el 
devenir de su trabajo. A pesar de ello, será a partir de La vida mantis donde su uso y profundización acerca de su naturaleza cobren mayor relevancia y significación. Ya en el año 1987, refiriéndose a una publicación anterior, el poeta se planteaba la cuestión del siguiente modo:

Nervadura es a la vez un poema y un recorrido por el terreno de un poema. Eso sí fue pensado de antemano. El libro fue pensado como estructuras mínimas, como filamentos que desembocaran en el poema final, que hacía la vez de una concentración de los textos anteriores, al mismo tiempo que una recuperación de ciertos indicios (Zapata 246).

Es preciso tener en cuenta en este sentido que, además de lo ya señalado previamente sobre la construcción de Nervadura, los poemas que pasan de Estación, estaciones a este libro no son transvasados de uno a otro texto como si de dos simples recipientes se tratase. Muy al contrario, sufren un proceso de fragmentación que provoca que cada uno de los poemas originales se convierta ahora en tres, cuatro o cinco textos diferentes. Por otro lado, a esta consideración general en cuanto a la fragmentación de la composición, la de los poemas de Nervadura en este caso, habría que añadir aquella que se refiere a la propia construcción del poema y que viene claramente expresada en la referencia de Milán a esas "estructuras mínimas" o "filamentos" que constituyen los textos. De esta manera, frente a un tipo de estructura plenamente cohesionada y en la que sus piezas quedan subsumidas bajo la dirección de un todo unitario, el poeta apuesta por la disparidad e independencia de cada elemento, desarrollando un procedimiento compositivo que, tal y como se verá, posee un carácter marcadamente simbólico-alegórico ${ }^{4}$.

En este sentido, también en un poema posterior a los dos libros más arriba mencionados, Eduardo Milán continúa haciendo hincapié en esa idea de lo incompleto y quebrantado que, como se decía, marca la trayectoria de prácticamente toda su escritura. Así, en Errar e insistiendo igualmente en la reflexión en torno al lenguaje y su empleo en el poema, se lee: "Real es la palabra más bella de este reino / en ruinas, real" (56). Sin embargo, a pesar de lo evidente del planteamiento, será a partir de La vida mantis donde estos procedimientos se hagan más patentes y cobren mayor importancia. Por ello,

$4 \quad$ Así lo ha hecho explícito José Luis Brea: "tal uso paratáctico ha de confiar a la interrupción del discurso su voluntad estratégica: pues no hay, en efecto, alegoría donde no hay corte, fragmentación en tanto sólo en él ocurre desvío de la significancia” (127). 
a la cita de Lezama Lima que abría este libro, y comentada previamente, habría que sumar ahora la segunda con la que el poeta enmarca sus textos; una breve referencia de Paul Klee: "Lo esencial, lo en verdad productivo es el camino -después de todo, devenir es superior a ser" (13). Lo interesante de esta máxima -que Milán hace suya-reside aquí en que con ella trata de hacer explícito que su postura frente a la escritura poética se correspondería con aquella en la que lo importante sería, antes que el resultado final, el propio procedimiento. Y de ahí justamente la necesidad de buscar en la forma y el proceso de configuración de la misma los significados de fondo del poema, en detrimento de la consecución e interpretación de un texto cerrado y completamente acabado, que habitualmente se le presupone. Así, partiendo de esa tensión producida entre la fracción y el conjunto, lo cambiante y lo estable, lo efímero y lo permanente, el poeta pone en conflicto entidades contrapuestas, sustentadas justamente sobre la base de la dualidad sobre la que se viene hablando: lo definido y completo frente a lo provisorio y fragmentario. Asimismo, tal dicotomía presenta como cuestión de fondo aquel deseo de imbricar en el lenguaje, sistema de representación necesariamente insuficiente e incompleto, la realidad en tanto que conjunto inabarcable.

Con tal perspectiva, se hace posible llegar ya al comienzo del primer poema de La vida mantis con una idea más o menos definida de la dirección que tomarán, a partir de ahora, todas las muestras relativas a la fragmentariedad y la volatilidad del sentido ofrecidas por el poeta: "Entro en el tiempo como quien entra / en ti: quiero escribir los deshechos / de San Juan, quiero comer los deshechos de Sor / Juana" (15). De este modo, la primera estrategia empleada por Milán aquí consiste en llevar a cabo una ruptura de la temporalidad-entrar en el tiempo-, que posibilite la fractura de la línea temporal en el poema y, así, puedan darse cita en un mismo espacio diferentes fragmentos temporales extraídos del conjunto de la existencia. En este sentido, Antonio Méndez Rubio certifica que "el mundo acontece en el poema como estallido, como apertura o espaciamiento. De ahí el flujo discontinuo, la lógica del salto, el carácter fragmentario" (246). Por otra parte, resulta especialmente significativo que, en este proceso de desmembración, lo único que el sujeto poético acepta como rescatable no son otra cosa que "deshechos", algo aparentemente inservible, nimio y sin la capacidad de dar una imagen fija u ofrecer algo completo. Si profundizamos más en la imagen de Milán nos encontramos con el poema de Sor Juana Inés de la Cruz en el que aparece el "deshecho": 
Esta tarde, mi bien, cuando te hablaba, $[\ldots]$

con sombras necias, con indicios vanos, pues ya en líquido humor viste y tocaste mi corazón deshecho entre tus manos (126).

En este poema puede apreciarse, además de una posible lectura en torno a la retórica del 11 anto ${ }^{5}$, cómo la acción descrita termina por ubicar un órgano -metafóricamente hablando, entiéndase- en las manos, sacándolo del lugar habitual en el que cumple una función vital para separarse del cuerpo y convertirse, según nuestra lectura, en un fragmento. Para Eduardo Milán, este desprendimiento supone la esencia de lo que considera fragmentario:

Eso es la escritura. Una escritura es más o menos fragmentaria. Pero no puede escapar al fragmento. El fragmento es un testimonio en sí mismo. Testifica un todo como parte. Es un desprendimiento, palabra que me gusta: primero, porque define el fragmento. Luego, $\mathrm{o}$ antes, porque es un des-prendimiento, un liberarse de los captores malditos en estos territorios de captores [...] El fragmento es, de nuevo, la imagen de un desprendimiento que tenía signo negativo en la medida en que abandonó una pertenencia, de des-prendió. El fragmento positiviza el desprendimiento, recuerda la parte y sigue sin ella (Salir fuera 115).

En la enunciación de Milán es justamente esto lo que cobra especial importancia: esa minúscula porción, esa pequeña parte que ha quedado fuera del conjunto y que, en innumerables ocasiones, ha sido entendida en tanto que ruina de una unidad perdida. Pero lejos de toda consideración negativa de la ruina, en tanto que fragmento o porción de un todo perdido, Milán la toma como elemento fundamental de la creación y de la vida ${ }^{6}$. Por ello, no debe confundirse esta alusión a las partes, los pedazos y lo fragmentario con

$5 \quad$ En la edición de 1692 este poema aparece acompañado por el epígrafe "En que satisface un recelo con la retórica del llanto", atribuido a Juan de Orúe. Para una mayor profundización en este sentido de ver La poética del llanto en Sor Juana Inés de la Cruz de Aurora González Roldán.

6 Será preciso resaltar la afinidad mantenida entre la idea de fragmento en Milán y la defendida por el romanticismo de Jena: "También en poesía todo lo que está acabado puede estar incompleto, y todo lo incompleto formar, en realidad, algo acabado" (Schlegel 29). 
cierto anhelo por una unidad ausente. Para Milán no constituyen un resquicio fetichista mediante el cual alcanzar o lograr restablecer el conjunto, sino que poseen valor en sí mismos, en virtud de su potencial para sugerir y ofrecer más de lo que aparentemente hay:

fragmento es discontinuidad, interrupción, resto, hueco, socavón, extracto, parte. Y mímesis de escritura de algo afuera: universo en expansión, por ejemplo. Y arriba, constelación, para Mallarmé. La escritura que está de lo que no está, sería una definición aproximada. Pero el fragmento riñe con la definición. En todo caso, y en especial para estos tiempos: incompletud. Con la ambigüedad siguiente: no se sabe si no alcanza o si dejó de ser, si va o viene (Un ensayo sobre poesía 40-41).

Con esta definición aportada por Eduardo Milán se logra ubicar todo lo ensayado anteriormente sobre una de las cuestiones clave a la hora de comprender el funcionamiento y función de esas "estructuras mínimas" en su poética. Y se trata justamente de cómo esos fragmentos, entendidos desde el mismo punto de vista sustentado por Milán, es decir, no como icebergs de algo oculto, sino como muestra -recordemos "interrupción, resto, hueco, socavón, extracto, parte"-, se vuelven alegóricos. En efecto, el interés de lo alegórico por presentar un significado diferente, más allá del puramente referencial, exige como primera medida extraer a las palabras del entramado construido por el lenguaje de uso cotidiano y comunicacional. Con esta maniobra el procedimiento alegórico desconecta los términos del conjunto del sistema lingüístico, así como de sus lecturas habituales, a fin de componer un nuevo sentido basado justamente en la capacidad de los elementos incompletos con los que ahora cuenta para evocar multitud de interpretaciones. Así, siguiendo las consideraciones de Benjamin, resulta posible afirmar que "en el campo de la intuición alegórica, la imagen es fragmento, runa. Su belleza simbólica se volatiliza al contacto de la luz de lo teológico, resultando con ello disipada la falsa apariencia de totalidad" (El origen del Trauerspiel alemán 395). De ahí también que la manera de proceder del poeta acuse cierta indeterminación semántica, en la que no solo podemos señalar el poema como fragmento, sino el hecho de que este a su vez se componga de fragmentos. Un claro ejemplo es la combinación de hablas, registros y situaciones lingüísticas; desde el plurilingüismo, pasando por la mezcla de coloquialismos con cultismos a extractos más propios de la conversación hablada, junto a otros que podrían calificarse de ensayísticos. Tal método de trabajo, en apariencia falto de 
sentido, es defendido nuevamente por el filósofo alemán alegando que el procedimiento alegórico supone una selección arbitraria, es decir, caprichosa pero no estéril, mediante la que se pretende unir una serie de piezas a través de combinaciones no preestablecidas. Por esto mismo, el resultado puede llegar a ser impredecible, ya que no existe una mediación orgánica entre las partes.

\section{CONCLUSIÓN}

De esta manera, con lo expuesto hasta aquí, la independencia de las series termina por adquirir un orden, el alegórico, en el que las relaciones de los términos no se fundan ya en una lógica basada en el desarrollo lineal, sino acumulativo y de yuxtaposiciones. De ahí que tomar consciencia del método que subyace al trabajo poético, se vuelva decisivo para analizar el texto. De igual modo, es preciso resaltar el hecho de que en este entramado alegórico se aprecia claramente la introducción de un nuevo componente, determinante para la comprensión de la estructura. Es aquello que Peter Bürger, apoyándose en Benjamin, planteaba del siguiente modo: "Lo alegórico arranca un elemento a la totalidad del contexto vital, lo aísla, lo despoja de su función. La alegoría es, por tanto, esencialmente un fragmento, en contraste con el símbolo orgánico" $(131)^{7}$. Así, no es solo el lenguaje quien sufre aquella maniobra de partición, sino que también la misma experiencia a la que este alude es entendida como trama de hechos y sucesos heterogéneos, imposible de aprehender en tanto que conjunto unitario. De hecho, es justamente esta razón la que explica la elección de la alegoría y el símbolo, en tanto que inadecuación entre forma y contenido, como vías de acceso y estructuración de una realidad múltiple: "la elección formal es ya una toma de partido ético y debe ser sostenida como si fuera una visión del mundo" (Trata de no ser un constructor 49) ${ }^{8}$, en palabras del propio Milán.

$7 \quad$ En este sentido, es preciso tener en cuenta aquí que la noción de símbolo a la que se está refiriendo Bürger, esa "orgánica", sería la diametralmente opuesta a aquella que ensalzaba su indeterminación, defendida por los autores del Romanticismo (Hegel, Creuzer y Bachofen), sobre la que se asienta nuestro acercamiento.

Resulta significativo aquí el título de este volumen, Trata de no ser un constructor de ruinas, en el que el autor continúa insistiendo en la idea de no restituir las faltas de la ruina y considerarla de por sí, evitando tener que referirla al conjunto. 
Por otro lado, esta fórmula no debe ser igualada por completo con aquella descrita anteriormente en torno a la imaginación, ya que responde a planteamientos diferentes, aunque no contradictorios. Si en el caso de la primera, la creación partía de un hecho posible, aunque no necesariamente real, en la segunda el componente vivencial sí se hace especialmente relevante. Sin embargo, a pesar de la disparidad de orígenes, ambas cumplen con el mismo propósito de conexión entre escritura y realidad y ambas hacen descansar su sentido en la forma. El poeta expresa esta dialéctica del siguiente modo: "cosas vividas, los que viven en la imagen" (Nivel medio verdadero 125). De ahí que, para Eduardo Milán, la imaginación no sea una fuente de invención ex nihilo, por el contrario, esta siempre responde a algo que está previamente pero que en la forma toma una disposición diferente con el fin de volverse más efectivo. Así lo sugiere y pone en práctica el autor en el siguiente texto:

\author{
¿Crear? Inventar lo que tenemos dentro \\ con la ayuda de las formas de afuera, rasantes \\ ranas de croar haikús, estandartes que están pájaros \\ de altos. Era primavera cuando el pájaro de adentro \\ coincidió con el cardenal de afuera, era \\ primavera en el punto final de las dos formas: \\ punto de fuego, gota púrpura a punto de desaparecer cercada \\ de azul, paso de sangre completa a nada completa coronada \\ por el éxito de la salida: Exit. Éxtasis, cien por ciento \\ de desaparición, ni cenizas desde donde nacer. \\ Dos formas que se funden en la oscuridad del cisne \\ atraídas por el último canto de la imagen, por el asiento, \\ sinsentido, \\ aún caliente. Nada de los pájaros. Extrema blancura sin \\ estremecimiento. Y eso que era primavera (130).
}

Así, en los primeros versos resume esos dos procedimientos empleados: por una parte, la puesta en marcha de la imaginación y, por la otra, la combinación de diversos elementos que dan entrada a lo vivencial en el poema. En ambos casos el contenido es el mismo, puesto que tanto lo puramente exterior como lo interior han pasado por el trabajo creativo del poeta. Se trata pues de un intento de creación a través de lo que Adorno denominaba como contenido de verdad en la obra, es decir, la capacidad de las prácticas estéticas para hacer un uso crítico del binomio idea-expresión. 
Asimismo, estas dos formas de actuación, por cuanto representan un determinado concepto de combinación, nos acercarían a otra de las nociones fundamentales del sentido alegórico, tal y como se viene planteando: el montaje ${ }^{9}$. Peter Bürger lo define del siguiente modo: "es una categoría que permite establecer con exactitud un determinado aspecto del concepto de alegoría. El montaje supone la fragmentación de la realidad y describe la fase de construcción de la obra" (137). Si como se veía, el mundo, el afuera, la realidad, se entiende de modo fragmentario, el sentido otorgado a la misma deberá centrarse en el procedimiento, es decir, en el camino hacia la formación del poema. Una finalidad que nunca llega ni concluye, puesto que las posibilidades de asociación ofrecidas por el montaje hacen que la alegoría, el decir más, y el símbolo, el que haya más que decir, logren cumplir su función. En ese caso, el fragmento funcionaría como "una escritura y un pensamiento no acabados, que no generan en el lector la sensación de que todo ya está bien, que el mundo tiene un orden, que ya estamos completos, como suelen ofrecer los tratados" (Milán, Resistir 41). De esta manera, se rompe con una estructuración del conocimiento y el discurso en la que todo respondía a un orden y a una jerarquización fija y se pasa a una situación en la que "las partes se emancipan de un todo situado por encima de ellas, al que se incorporaban como componente necesario" (145), de nuevo en palabras de Bürger. Así, como apuntábamos anteriormente, las partes cobran una relevancia significativa como entes autónomos, sin la necesidad de un todo que les dé sentido. Por ello, los poemas se componen de materiales heterogéneos que encuentran o buscan un sentido otro y que mantienen su unidad en la propia indagación y uso de técnicas disímiles. De ahí que esta constante reformulación y sondeo hagan del poeta un ser disconforme, siempre atento a la posibilidad de alcanzar un sentido que sabe inestable $\mathrm{y}$, por tanto, mudable y en perpetuo cambio. Es decir, trata de transformar su insatisfacción en impulso de la propia escritura poética. Así, el poeta, consciente de la movilidad y el cambio inherente a lo real, se propone un ensayo continuo con el que aplacar la inquietud que le provocan. Por otro lado, bajo este mismo diagnóstico, con la defensa de la ambigüedad inherente a lo simbólico y la plurisignificación de lo alegórico, apuesta por dotar de un sentido múltiple a su escritura, a través de estos procedimientos, ante la

9 Para una mayor sistematización del concepto, tanto en relación con su historia como con su implicación en otras artes, ver Estética del montaje de Vincent Amiel. 
imposibilidad de cercar de forma plena lo real. De este modo, los símbolos de la poesía de Milán terminan por mostrarse como formas de extraordinaria capacidad semántica, donde la inadecuación total entre figura y contenido más que como obstáculo es entendida en tanto que oportunidad para abarcar nuevas propuestas interpretativas sobre el mundo. Asimismo, sus símbolos, en apariencia convencionales y simples (pájaro, roca, desierto, pez, etc.), han mostrado la necesidad de ser referidos a la tradición literaria más codificada, pero también a la posición adquirida por la tensión con esta y el conjunto de la obra del poeta, si se pretendía comprenderlos en todo su alcance.

\section{BIBLIOGRAFÍA}

Adorno, Theodor. Teoría estética. Trad. Jorge Navarro. Madrid: Akal, 2004.

Amiel, Vincent. Estética del montaje. Trad. Monique Perriaux y Vicente Carmona. Madrid: Abada, 2005.

Benjamin, Walter. El origen del Trauerspiel alemán. Obras Completas, libro 1 vol. 1. Trad. Alfredo Brotons Muñoz. Madrid: Abada, 2008. 217-459.

"Parque Central". Charles Baudelaire. Un lírico en la época del altocapitalismo,

Obras Completas, libro 1 vol. 2. Trad. Alfredo Brotons Muñoz. Madrid: Abada. 2008. 87-301.

Brea, José Luis. Nuevas estrategias alegóricas. Madrid: Tecnos, 1991.

Bürger, Peter. Teoría de la vanguardia. Trad. Jorge García. Barcelona: Península, 2000.

Casado, Miguel. "El insumiso decir. Eduardo Milán". La experiencia de lo extranjero. Barcelona: Galaxia Gutenberg, 2009. 317-322.

Chacón, Alfredo. Poesía y poética del grupo Orígenes. Caracas: Biblioteca Ayacucho, 1994.

Cruz de la, Sor Juana Inés. "Esta tarde, mi bien, cuando te hablaba". Obra selecta. Caracas: Biblioteca Ayacucho, 1994.

Franco, Jean. Decadencia y caída de la ciudad letrada: La literatura latinoamericana durante la guerra fría. Barcelona: Debate, 2003.

González Roldán, Aurora. La poética del llanto en Sor Juana Inés de la Cruz. Zaragoza: Prensas Universitarias de la Universidad de Zaragoza, 2009.

Méndez Rubio, Antonio. "Milán por Antonio Méndez Rubio". Disenso. Eduardo Milán. Ed. México: Fondo de Cultura Económica, 2010. 245-247.

Mendiola, Víctor Manuel. “¿Rehabilitación del significado?”. Errar. Eduardo Milán. Ed. México: El tucán de Virginia, 1991. 7-13.

Milán, E. 1991. Errar. México: El tucán de Virginia, 1991. La vida mantis. México: El tucán de Virginia, 1993. Nivel medio verdadero de las aguas que se besan. Madrid: Ave del Paraíso, 1994. 
Resistir: Insistencias sobre el presente poético. México: Fondo de Cultura Económica, 1994. Cuatro poemas. Manto. México: Fondo de Cultura Económica, 1999. 57-61. Trata de no ser un constructor de ruinas. Guadalajara: Filodecaballos, 2003. Acción que en un momento creí gracia. Tarragona: Igitur, 2005. Un ensayo sobre poesía. Tlalpan: Ácrono producciones y Libros del umbral, 2006. "Palabras clave. Unas palabras que defender. No todo se negocia". Salir fuera: Tierra de ensayos. Tenerife: Baile del Sol, 2013.

Ochoa, Antonio. "Milán por Antonio Ochoa”. Disenso. Eduardo Milán. Ed. México: Fondo de Cultura Económica, 2010. 235-239.

Schlegel, Friedrich. Fragmentos, seguido de Sobre la incomprensibilidad. Trad. Pere Pajerols. Barcelona: Marbot, 2009.

Szondi, Peter. Poética y filosofía de la historia I. Trad. Francisco L. Lisis. Madrid: Antonio Machado, 1992.

Todorov, Tzvetan. Literatura y significación. Trad. Gonzalo Suárez Gómez. Barcelona: Planeta, 1971.

Teorías del símbolo. Trad. Francisco Rivera. Caracas: Monte Ávila Editores, 1991.

Vélez, Nicanor. "Eduardo Milán: el no-lugar del poeta". Querencia, gracias y otros poemas. Barcelona: Galaxia Gutenberg / Circulo de Lectores, 2003. 7-38.

Zapata, Miguel Ángel. "Eduardo Milán: el poeta en el paisaje del texto, entrevista y selección de poemas". Inti, revista de literatura hispánica 26-27 (1987): 245-253. 